\title{
Prevalence of Malocclusion in Primary Dentition in Southeast Part of Haryana, India: A Cross-sectional Study
}

\author{
Kapil Sharma ${ }^{1}$, Tanvi Bihani², Vineet Kumar ${ }^{3}$
}

\begin{abstract}
Objective: The purpose of this study was to assess the prevalence of malocclusion in primary dentition of children in southeast part of Haryana state in India.

Materials and methods: About 1,540 children of age 3-5 years from 10 nursery and 10 primary schools were selected across Rohtak city. The children were selected by stratified random technique and examined at their respective schools. Oral examination was done to record the parameters such as molar relation, canine relation, crowding, spacing, midline shift, overjet, overbite, rotations, supernumerary teeth, tooth wear, anterior crossbite, and open bite. Chi-square test was used for calculating $p$-value.

Results: Class I canine relations was seen in $66.2 \%$, flush terminal plane, mesial step, and distal step were observed in $60 \%, 30.8 \%, 9.2 \%$, respectively. Midline shift was observed in $1.8 \%$ in maxilla and $4 \%$ cases in mandible. Rotations were more prevalent in mandibular dentition (26\%). Supernumerary teeth were found to be $0.4 \%$ in maxillary arch. Spacing was reported in $81.9 \%$ in maxillary dentition and $69 \%$ in mandibular dentition. Increased overjet and overbite was present in $10.3 \%$ and $30.9 \%$, respectively. Anterior crossbite and anterior open bite were seen in only $1 \%$ and $1.9 \%$ children, respectively with statistically significant higher prevalence in males. Prevalence of attritional facets were reported $13 \%$ in enamel and $8 \%$ in dentin.

Conclusion: There is a high prevalence of class I canine relation, flush terminal plane molar, and spaced dentitions, suggestive of low prevalence of malocclusion in primary dentition in Rohtak district of Haryana state. The results may provide a baseline data for further research on a larger scale. Keywords: Flush terminal plane, Occlusal characteristics, Primary dentition.

International Journal of Clinical Pediatric Dentistry (2021): 10.5005/jp-journals-10005-2158
\end{abstract}

\section{INTRODUCTION}

Malocclusion is a developmental anomaly of dental arches that may occur in both primary and permanent dentition. It is a well-known fact that if discrepancies were found in occlusal characteristics of deciduous dentition, then there are high chances of getting the similar occlusal problems in the succeeding permanent teeth. ${ }^{1}$ Generally, etiology of malocclusion involves interaction of hereditary, congenital, and acquired factors. Depending upon the severity of malocclusion, it may cause esthetic discomfort, functional damage and disability. ${ }^{2}$ The dictum "the early age is the golden age" always holds good to treat malocclusion. If a malocclusion is identified early, the developing malocclusion can be treated with the help of preventive and interceptive measures. Flush terminal plane molar relationship, spaced dentition, less overjet, and overbite are characteristic features of primary dentition.

To determine the oral health status of population and to see the changes in occlusion during growing stages of children, the role of epidemiological studies is important. Very few literatures are available on the occlusal characteristics of primary dentition in India, as most of the studies have done on children above 6 years of age. Thus, the present study was undertaken to obtain baseline information about occlusion and its characteristics in 3-5 years old children in Rohtak district of Haryana, India.

\section{Materials and Methodology}

The present study was conducted in the Department of Pedodontics and Preventive dentistry of Post Graduate Institute of Dental Sciences, Rohtak. The study was based on the examination of 1,540 Children aged between 3 and 5 years, out of which 770 were
${ }^{1}$ Department of Dental Sciences, Health Services, Nirwana, Haryana, India

${ }^{2}$ Department of Dentistry, SHKM Government Medical College, Nalhar, Haryana, India

${ }^{3}$ Department of Prosthodontics, Crown and Bridge and Implantology, Rajasthan Dental College and Hospital, Jaipur, Rajasthan, India

Corresponding Author: Tanvi Bihani, Department of Dentistry, SHKM Government Medical College, Nalhar, Haryana, India, Phone: +91 9928935333, e-mail: bihani.tanvi@gmail.com

How to cite this article: Sharma K, Bihani T, Kumar V. Prevalence of Malocclusion in Primary Dentition in Southeast Part of Haryana, India: A Cross-sectional Study. Int J Clin Pediatr Dent 2021;14(6):757-761.

Source of support: Nil

Conflict of interest: None.

males and 770 were females. Selection of children were done from nursery and primary schools spreading over four geographic zones of Rohtak city (north, south, east, and west) of Haryana. Five schools were selected randomly from each zone. Thus a total of 20 schools, 10 from nursery and 10 from primary sections were selected for the study. The children were selected by stratified random technique and examined at their respective schools. The age, address, and socioeconomic status was obtained from their school records. The examination was performed under daylight in the classroom. Clinical evaluation was performed on all children in upright position and biting in maximal intercuspation in compliance with the international standards of infection control protocol in a classroom setting. The Foster and Hamillton ${ }^{4}$ criteria was applied in

() The Author(s). 2021 Open Access This article is distributed under the terms of the Creative Commons Attribution 4.0 International License (https://creativecommons. org/licenses/by-nc/4.0/), which permits unrestricted use, distribution, and non-commercial reproduction in any medium, provided you give appropriate credit to the original author(s) and the source, provide a link to the Creative Commons license, and indicate if changes were made. The Creative Commons Public Domain Dedication waiver (http://creativecommons.org/publicdomain/zero/1.0/) applies to the data made available in this article, unless otherwise stated. 
the assessment of the prevalence of malocclusion in the deciduous dentition in an examination chart.

After the due ethical clearance by the institutional ethical committee, consent was obtained from concerned school authorities as well as from concerned district education officer.

\section{Inclusion Criteria}

- Children in between the age of 3 and 5 years.

- Health and age-appropriate physical development (within normal limit).

- Presence of only deciduous teeth with no erupted permanent teeth.

\section{Exclusion Criteria}

- Children having mixed and permanent dentition.

- Children having proximal caries.

- Uncooperative children and abnormal physical development.

Canine relation, molar relation, spacing, crowding, rotations, midline shift, overjet, overbite, anterior crossbite, and open bite were evaluated among 1,540 children.

Canine relation: When the cusp tip of the maxillary primary canine and distal surface of mandibular primary canine are in the same vertical plane then it is Class I canine relation. In Class II, the cusp tip of the maxillary primary canine tooth is mesial and in Class III it is distal to the distal surface of the mandibular primary canine. ${ }^{4}$ Molar relation was classified as flush terminal plane, mesial step, and distal step depending upon the relationship of distal surfaces of upper and lower second primary molar. ${ }^{5}$ Spacing was graded according to Kisling and $\mathrm{Krebs}^{6}$ criteria.

Overjet: Overjet is measured with the help of millimeter gauge, it is the distance between the incisal edges of the upper and lower primary incisors. It is registered as ideal overjet- when equal to $2 \mathrm{~mm}$, increased-more than $2 \mathrm{~mm}$, and decreased or reverse overjet in case of less than $2 \mathrm{~mm} .{ }^{4}$ Measurement of vertical overlapping of upper and lower central incisors is overbite. It was recorded as ideal, when incisal edges of lower incisors touches the palatal surfaces of the upper central incisors in centric occlusion, increased, if the lower incisors touches the palate, and when they are not in contact either with the upper incisors or the palate, recorded as reduced overbite. ${ }^{4}$

\section{Statistical Analysis}

The Microsoft Excel spreadsheet was made with the help of collected information, then coded correctly and later cleaned for any possible errors in SPSS (Statistical Package for Social Sciences) for Windows version 23. For categorical variables Pearson's Chi-square test was used to evaluate differences between independent groups. In case, expected cell count was less than 5 in $>20 \%$ cells, Fisher's exact test was used. All tests were performed at $5 \%$ level of significance, thus a difference was considered statistically significant if the $p$-value was less than 0.05 .

\section{Results}

Result showed that most prevalent canine relation was Class I that were present in $66.2 \%$ followed by Class II (33\%), and Class III $(0.8 \%)$ canine relation. No significant association was found between male and female (Table 1). Midline shifting was more common in mandible (4\%) as compared to maxilla (1.8\%). Flush terminal plane $(60 \%)$ was the commonest molar relation followed by mesial terminal plane (30.8\%) and distal terminal plane $(9.2 \%)$ in the examined population. (Table 2).

Prevalence of rotated teeth was more in mandibular arch (26\%) as compared to maxillary arch (9\%) (Table 3). Supernumerary teeth was found $0.3 \%$ in maxillary arch only of the examined children. Crowding was reported $18 \%$ in maxillary dentition and $31 \%$ in mandibular dentition (Fig. 1). Spacing was present in $81.9 \%$ in maxillary dentition and $69 \%$ in mandibular dentition (Fig. 2). Nearly $10.3 \%$ cases were of increased overjet and overbite was present in $30.9 \%$, whereas reduced overjet and overbite was noticed in $1.2 \%$ and $9.7 \%$, respectively in the examined children (Figs. 3 and 4).

Anterior crossbite was seen in 15 (1\%) children, out of which 11 were males and 4 were females (Table 4). Statistically significant prevalence was present in males. Anterior open bite was reported in $1.9 \%$ children with statistically significant higher prevalence in males than females (Table 5). Prevalence of attritional facets were reported $13 \%$ in enamel and $8 \%$ in dentin.

\section{Discussion}

At the age of 3 years, the deciduous teeth are completely erupted and establishing their occlusal relationship which last at the age of 6 years until the first permanent tooth begins to erupt in the oral cavity. ${ }^{7}$ For early interceptive treatment, it is important to understand the relationship between primary and early permanent dentition. ${ }^{8}$ In this study, Class I (87\%) canine relation was most common followed by Class II (8\%) and Class III (5\%) in age group of 3-5 years. Similar results were found by Shavil RG et al. ${ }^{9}$ in primary dentition of children of Davangere city in which Class I canine relation was found to be more prevalent (90\%) followed by Class II (6.4\%) and Class III (6\%) and Vegesna $\mathrm{M}$ et al. ${ }^{10}$ in 3-6 years old Dravidian children found that Class I canine relation to be more prevalent (81.3\%) than Class II (5.9\%) and Class III (5.8\%). On the contrary, study conducted in Gurugram by Yadav NR et al. ${ }^{11}$ noted the prevalence of Class I canine relation (67.2\%) was much less than the prevalence recorded in our study and they also noted increased prevalence of Class II canine relation that is, $31.6 \%$, whereas study conducted in Nigerian children by Otuyemi OD et al. ${ }^{12}$ found increased prevalence of Class III canine relation (20.2\%).

In our study, flush terminal plane $(60 \%)$ and mesial step relationships (30.8\%) were observed with high prevalence. Similar results were seen by Bhayya DP et al. ${ }^{13}$ study in Bagalkot city of India, that $52.5 \%$ had a flush terminal molar relationship. A study conducted by Yadav NR et al. ${ }^{11}$ found that flush terminal plane

Table 1: Distribution of canine relation by gender of subjects $(n=1,540)$

\begin{tabular}{lcccc}
\hline \multirow{2}{*}{ Gender } & \multicolumn{3}{c}{ Canine relation } & \multirow{2}{*}{ Significance* } \\
\cline { 2 - 3 } & Class I & Class II & Class III & \\
\hline Male $(n=770)$ & $512(66.4 \%)$ & $251(31.4 \%)$ & $7(0.9 \%)$ & $p=0.917$ \\
Female $(n=770)$ & $507(65.8 \%)$ & $257(34.7 \%)$ & $6(0.8 \%)$ & not significant \\
Total $(n=1,540)$ & $1,019(66.2 \%)$ & $508(33.0 \%)$ & $13(0.8 \%)$ & \\
\hline
\end{tabular}


Table 2: Distribution of molar relation according to gender of subjects

\begin{tabular}{|c|c|c|c|c|}
\hline \multirow{2}{*}{ Gender } & \multicolumn{3}{|c|}{ Molar relation } & \multirow{2}{*}{ Significance* } \\
\hline & FTP & $M S$ & $D S$ & \\
\hline Male $(n=770)$ & 477 (61.9\%) & 231 (30.0\%) & $62(8.2 \%)$ & \multirow{3}{*}{$\begin{array}{c}p=0.169 \\
\text { (not significant }\end{array}$} \\
\hline Female $(n=770)$ & 447 (58.1\%) & 243 (31.6\%) & 80 (10.4\%) & \\
\hline Total $(n=1,540)$ & $924(60.0 \%)$ & $474(30.8 \%)$ & $142(9.2 \%)$ & \\
\hline
\end{tabular}

Table 3: Distribution of rotation according to gender of subjects

\begin{tabular}{lccc}
\hline \multirow{2}{*}{ Gender } & \multicolumn{2}{c}{ Rotation } & Significance* $^{*}$ \\
\cline { 2 - 3 } Male $(n=770)$ & Maxillary arch & Mandibular arch & \\
Female $(n=770)$ & $71(9.2 \%)$ & $97(12.6 \%)$ & $p=0.59$ \\
Total $(n=1,540)$ & $67(8.7 \%)$ & $103(13.4 \%)$ & (not significant) \\
\hline
\end{tabular}

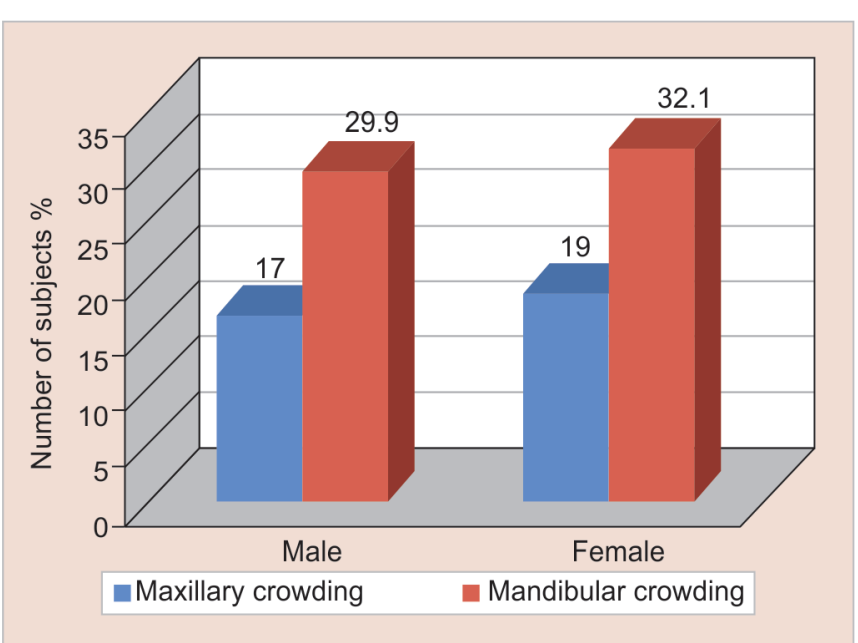

Fig. 1: Distribution of crowding of teeth according to gender of subjects

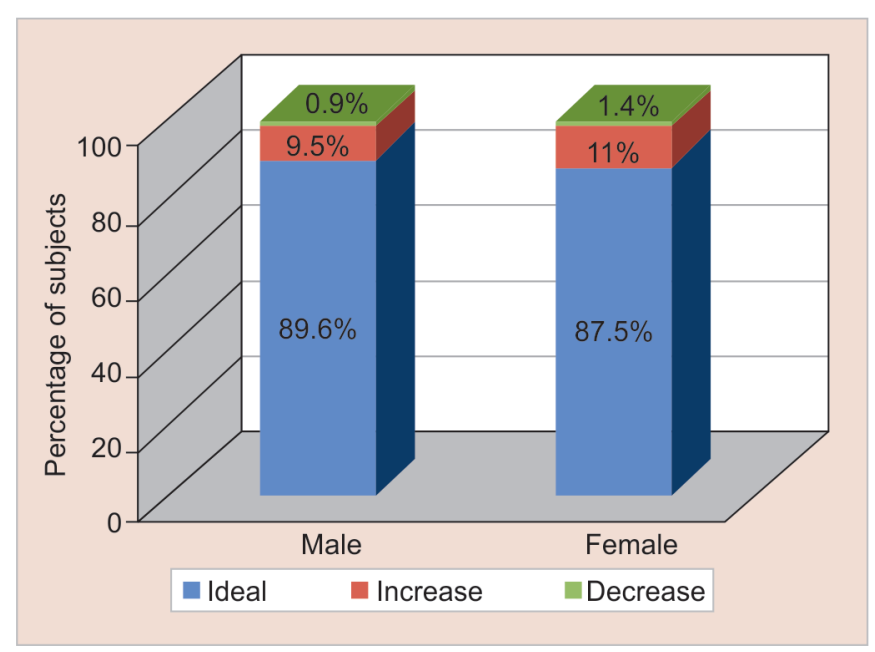

Fig. 3: Distribution of overjet of teeth according to gender subjects

(62.4\%) was prevalent in Gurugram population followed by mesial step (25.2\%) and distal step molar relationships (12.4\%). A study done by Adersona $A A^{14}$ found mesial step molar relationship was more prevalent in both the African American and European children, which was opposite to our results. According to Clinch $\mathrm{LM}^{15}$ normally molar relationship in primary dentition was straight

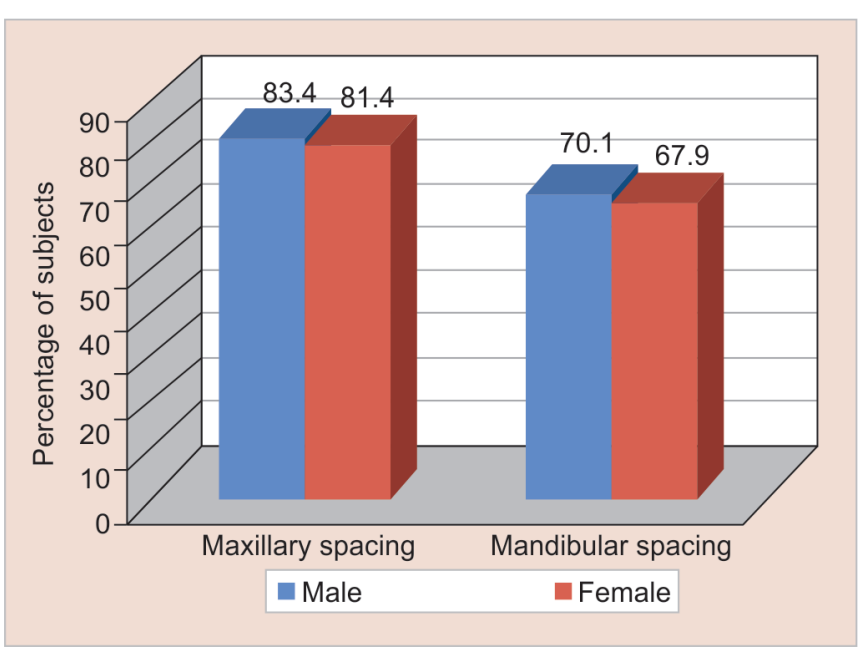

Fig. 2: Distribution of spacing of teeth according to gender of subjects

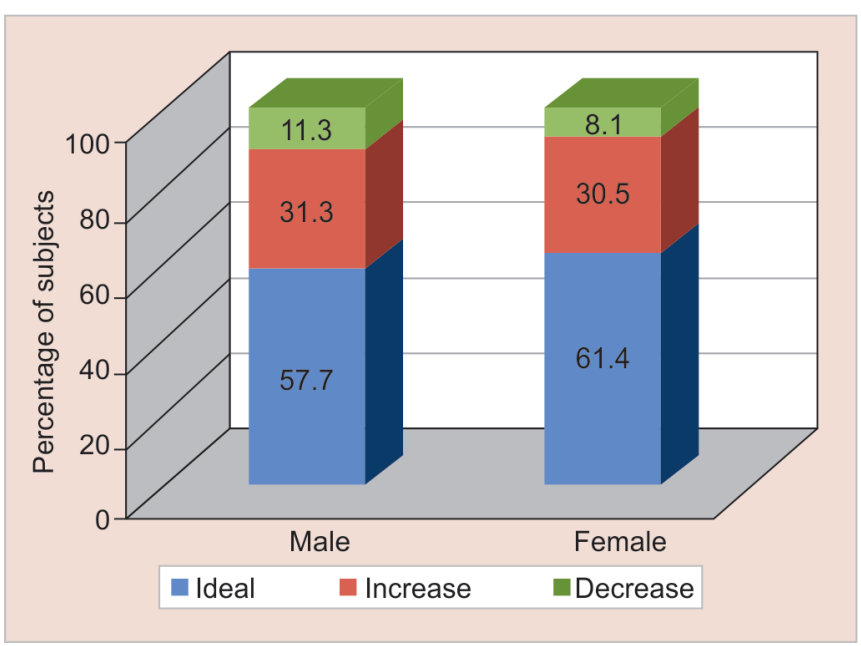

Fig. 4: Distribution of overbite according to gender of subjects

(flush) until eruption of permanent first molar. However many studies had claimed straight or mesial terminal planes is normality and our findings also support the same.

Midline shift were present in $5.84 \%$ children in our study with a higher prevalence in boys and in mandible, similar finding was seen by Bhayya DP et al. ${ }^{11}$ in Bagalkot city of India (6\%), the study done 
Prevalence of Malocclusion in Primary Dentition

Table 4: Distribution of anterior crossbite according to gender of subjects

\begin{tabular}{|c|c|c|c|}
\hline \multirow{2}{*}{ Gender } & \multicolumn{2}{|c|}{ Anterior crossbite } & \multirow{2}{*}{ Significance ${ }^{*}$} \\
\hline & Number & Percentage & \\
\hline Male $(n=770)$ & 11 & $1.4 \%$ & \multirow{3}{*}{$\begin{array}{c}p=0.001 \\
\text { (significant) }\end{array}$} \\
\hline Female $(n=770)$ & 4 & $0.5 \%$ & \\
\hline Total $(n=1,540)$ & 15 & $1.0 \%$ & \\
\hline
\end{tabular}

Table 5: Distribution of anterior open bite according to gender of subjects

\begin{tabular}{|c|c|c|c|}
\hline \multirow{2}{*}{ Gender } & \multicolumn{2}{|c|}{ Anterior open bite } & \multirow{2}{*}{ Significance ${ }^{*}$} \\
\hline & Number & Percentage & \\
\hline Male $(n=770)$ & 21 & $2.7 \%$ & \multirow{3}{*}{$\begin{array}{c}p<0.001 \\
\text { (significant) }\end{array}$} \\
\hline Female $(n=770)$ & 9 & $1.2 \%$ & \\
\hline Total $(n=1,540)$ & 30 & $1.9 \%$ & \\
\hline
\end{tabular}

by Alamoudi $\mathrm{N}^{16}$ in Saudi Arabian children reported a prevalence of $10.5 \%$ which was higher than our results. The most common cause of dental midline shift is early shedding of the deciduous teeth that may lead to lack of space and midline discrepancy in the permanent dentition.

Crowding is one of the most common features in contemporary dentition. In our study, crowding was seen in 31\% in mandibular anterior teeth and $18 \%$ in maxillary dentition. These results were similar to a study done by Yadav et al. ${ }^{11}$ in Gurugram city of Haryana showed $31.2 \%$ crowding in mandibular arch and $6 \%$ in maxillary arch. The study done by Abu Alhaija and Qudeimet ${ }^{17}$ who reported crowding in $38.2 \%$ and $21.6 \%$ in upper and lower arches, respectively in Jordian preschool children which was higher than our study. In contrast, Bhayya DP et al. ${ }^{13}$ in Bhagalkot city of India found only $4.6 \%$ crowding in mandibular arch and $1.7 \%$ in maxillary arch. If there is crowding or tight contact is present in deciduous dentition then chances of crowding are increased in the permanent dentition. Generally, spacing should be present in all upper and lower primary teeth. In our study, we observed $81.9 \%$ of spacing in maxillary teeth and $69 \%$ in mandibular teeth with more common in males than females. Mostly spacing was present in the anterior region. The study conducted by Suma G and Das VM ${ }^{2}$ and Thailander B et al. ${ }^{18}$ also noted that spacing was more frequent in males and crowding was more in females but on contrary, study done by Yadav NR et al. ${ }^{11}$ in Farukhnagar, Gurugram reported spacing was more prevalent in females and crowding was more common in males that indicates there are high chances of malocclusion in permanent dentition in males rather than females.

In present study, $88.4 \%$ of examined population showed an ideal overjet, $10.3 \%$ have increased overjet and only $1.2 \%$ of study population showed decreased overjet (which includes anterior crossbite cases that are $1 \%$ of total sample).The results were in association with the study of Vegesna M et al. ${ }^{10}$ in Dravidian children and Yadav NR et al. ${ }^{11}$ in Haryana children found an increased overjet in $8.9 \%$ and $7.6 \%$, respectively. On the converse, Ravn ${ }^{19}$ found $27 \%$ of Copenhagen children have increased overjet whereas Foster and Hamilton ${ }^{4}$ reported a very higher percentage (72\%) of children with increased overjet.

About $59.41 \%$ of studied population had ideal overbite, while $30.9 \%$ had increased overbite and $9.7 \%$ were reported with decreased overbite which also included anterior open bite (1.9\%). Vegesna $\mathrm{M}$ et al. ${ }^{10}$ found that ideal overbite, increased overbite and decreased bite was seen in $72.7 \%, 19.4 \%$, and $2.5 \%$ of children, respectively which also includes $1.5 \%$ anterior open bite. Yadav NR et al. ${ }^{11}$ found an increased overbite in $12.4 \%$ of study population.
In the present study, attrition was noted in $20.9 \%$ of children, out of which enamel and dentin involvement were $13 \%$ and $8 \%$, respectively. Mild tooth wear can be considered as physiological process.

Anterior crossbite was found in $0.97 \%$ of children. In the study population of Deepak P Bhayya ${ }^{13}$ anterior crossbite was seen in $1.9 \%$ and $0.5 \%$ in a study population of Hegde $S^{20}$

In $1.9 \%$ of study population, Anterior open bite was seen. Contrary to our results, a prevalence of $37.4 \%$ in Caucasian children found by Tschill et al. ${ }^{15}$ and Thilander B et al. ${ }^{18}$ found prevalence of $10.7 \%$, which was very much higher than our study. In present study, no case of scissor bite and proclination was reported in deciduous dentition.

\section{Conclusion}

It can be concluded from our study that Class I canine relation, flush terminal plane molar relation, spaced dentition, ideal overjet, and overbite were amongst the most common occlusal characteristics found in our study population without any gender variation. Anterior crossbite and open bite were more prevalent in males than females. So our results, indicates that there are low prevalence of developing malocclusion in the primary dentition of Rohtak children in Haryana, India. For prevention and early management of dental malocclusion it is necessary to conduct a study including other and nearby area of Rohtak district with larger sample sizes.

\section{References}

1. Dutra ALT, Berto PM, Vieira LDS, et al. Longitudinal changes in the molar relationship from primary to permanent dentition. Con Scientiae Saude 2009;8(2):171-176. DOI: 10.5585/conssaude. v8i2.1640

2. Suma G, Das UM. Crowding, spacing and closed dentition and its relationship with malocclusion in primary dentition. Int J Clin Dent Sci 2010;1:16-19.

3. Joshi MR, Makhija PG. Some observations on spacing in the normal deciduous dentition of 100 Indian children from Gujarat. $\mathrm{Br}$ J Orthod 1984;11(2):75-79. DOI: 10.1179/bjo.11.2.75

4. Foster TD, Hamilton MC. Occlusion in the primary dentition: study of children at 21/2 to 3 years age. Br Dent J 1969;126(2):76-79.

5. Baume LJ. Physiological tooth migration and its significance for the development of occlusion: I. The biogenetic course of deciduous dentition. J Dent Res 1950;29(2):123-132. DOI: $10.1177 / 00220345500290020301$

6. Kisling E, Krebs G. Patterns of occlusion in 3 year old Danish children Community Dent Oral Epidemiol 1976;4:(4)152-159. DOI: 10.1111/ j.1600-0528.1976.tb00974.x 
7. Farsi NMA, Salama FS. Characteristics of primary dentition occlusion in a group of Saudi children. Int J Paediatr Dent 1996;6(4):253-259. DOI: 10.1111/j.1365-263x.1996.tb00254.x

8. Ngan PW, Wei SHY, Yen PKY. Orthodontic treatment of the primary dentition. J Am Dent Assoc 1998;116(3):336-340. DOI: 10.14219/jada. archive.1988.0224

9. Shavi GR, Hiremath NV, Shukla R, et al. Prevalence of spaced and non-spaced dentition and the occlusal relationship of primary dentition and its relation to malocclusion in school children of Davangere. J Int Oral Health 2015;7(9):75-78.

10. Vegesna M, Chandrasekhar R, Chandrappa V. Occlusal characteristics and spacing in primary dentition: a gender comparative cross-sectional study. Int Sch Res Notices 2014;2014:512680; DOI: $10.1155 / 2014 / 512680$

11. Yadav NR, Prasad S, Rajashekharappa CB, et al. Gender influence on occlusal characteristics in the primary dentition. APOS Trends Orthod 2014;4(4):87-92. DOI: 10.4103/2321-1407.135789

12. Otuyemi OD, Sote EO, Isiekwe MC, et al. Occlusal relationships and spacing or crowding of teeth in the dentitions of 3-4 year old Nigerian children. Int J Pediatr Dent 1997;7(3):155-160. DOI: 10.1046/j.1365-26 3x.1997.00232.x

13. Bhayya $D$, Shyagali T. Gender influence on occlusal characteristics of primary dentition in 4 to 6 year old children of Bagalkot City, India. Oral Health Prev Dent 2011;9(1):17-27.
14. Andersona AA. Occlusal development in children of African American descent: types of terminal plane relationships in the primary dentition. Angle Orthod 2006;76(5):817-823. DOI: 10.1043/0003-321 9(2006)076[0817:ODICOA]2.0.CO;2

15. Clinch LM. An analysis of serial models between three and 8 years of age. Dent Rec (London) 1951;71(4):61-72.

16. Salako N, Alamoudi N, Fateih R, et al. Prevalence and distribution pattern of interdental spaces in the primary dentition of Saudi Arabian children. J King Abdulaziz univ Med sci 1999;7(2):107-113. DOI: 10.4197/med.7-2.11

17. Abu Alhaija ESJ, Qudeimat MA. Occlusion and tooth/arch dimensions in the primary dentition of preschool Jordanian children. Int J Paediatr Dent 2003;13(4):230-239. DOI: 10.1046/j.1365-263x.2003.00466.x

18. Thilander $B$, Pena $L$, Infante $C$, et al. Prevalence of malocclusion and orthodontic treatment need in children and adolescents in Bogota, Colombia. An epidemiological study related to different stages of dental development. Eur J Orthod 2001;23(2):153-167. DOI: 10.1093/ejo/23.2.153

19. Ravn J J. Longitudinal study of occlusion in the primary dentition in 3- to 7-year-old children. Scand J Dent Res 1980;88(3):165-170. DOI: 10.1111/j.1600-0722.1980.tb01210.x

20. Hegde S, Panwar S, Rao Bolar D, et al. Characteristics of occlusion in primary dentition of pre-school children of Udaipur, India. Eur J Dent 2012;6(1):51-55. 